\title{
Avaliação cognitiva em idosos infectados por malária $P$. Vivax
}

\author{
Cognitive assessment in elderly infected with $P$. vivax malaria \\ Evaluación cognitiva en ancianos infectados con paludismo por $\boldsymbol{P}$. vivax
}

Recebido: 23/02/2021 | Revisado: 25/02/2021 | Aceito: 28/02/2021 | Publicado: 03/03/2021

\author{
Sabrina de Oliveira Marques \\ ORCID: https://orcid.org/0000-0001-7062-6517 \\ Faculdade Martha Falcão Devery, Brasil \\ E-mail:ipsi.sabrina@gmail.com \\ Samara de Oliveira Lima \\ ORCID: https://orcid.org/0000-0001-9218-1248 \\ Centro Universitário FAMETRO, Brasil \\ E-mail:samaradol_mara@gmail.com \\ Sanara Macedo Sousa \\ ORCID: https://orcid.org/0000-0002-6799-8704 \\ Centro Universitário UNINORTE, Brasil \\ E-mail:sanaranara@hotmail.com \\ Marilene Castilho de Almeida \\ ORCID: https://orcid.org/0000-0003-3959-1883 \\ Centro Universitário FAMETRO, Brasil \\ E-mail:marilene_castilho@hotmail.com
}

\begin{abstract}
Resumo
O presente artigo visa trazer pesquisas bibliográficas que relacionem a avaliação cognitiva em idosos e os possíveis danos causados pelo vírus da malária no Estado do Amazonas. Nos últimos anos houve um crescente número de idosos infectados por malária no estado. O propósito desta pesquisa é obter dados, que possa direcionar a avaliação psicológica para terceira idade. Para obtenções dos dados buscou-se por informações sobre o desenvolvimento humano, e a da infecção do vírus da malária, através de livros e artigos. Buscou-se por instrumentos que são utilizados na avaliação psicológica para coletar informações que mensuram habilidades cognitivas e funções executivas, levando ao conhecimento destes construtos no referencial teórico de Papalia, D. E, Olds. S. W, \& Feldman, R D (2006) Desenvolvimento humano e Charchat-Fichman, Helenice et al. (2005). Declínio da capacidade cognitiva durante o envelhecimento. Através dos resultados encontrados percebeu-se que a avaliação psicológica precisa de mais pesquisas sobre este tema, cognição e a malária. Conclui-se que através de novos estudos poderão surgir mais instrumentos psicométricos.
\end{abstract}

Palavras-chave: Cognição; Idoso; Malária P. vivax.

\begin{abstract}
The article seeks to present bibliographic researches that make relation between the cognitive evaluation in elderly people and the possible damages caused by the Malaria at the Amazonas state. The objective of this research is to obtain data that can direct the psychological evaluation to the third age. To the data getting, it was searched information about the human development and the malaria infection, through books and scientific articles. It was searched instruments used in the psychological evaluation to collect data about cognitive abilities and executive functions; it was considered the theoretical reference of Papalia, D. E, Olds. S. W, \& Feldman, R D (2006) Human development and Charchat-Fichman, Helenice et al. Decline of cognitive abilities during aging (2005). By the found results it was possible to perceive that the psychological evaluation lacks more researches in the theme, cognition and malaria. It was concluded that new studies may lead to more psychometric instruments.
\end{abstract}

Key-words: Cognition; Elderly; Malaria P. vivax.

\section{Resumen}

Este artículo tiene como objetivo acercar la investigación bibliográfica que relacione la evaluación cognitiva en el anciano y el posible daño causado por el virus de la malaria en el Estado de Amazonas. En los últimos años ha habido un número creciente de personas mayores infectadas con malaria en el estado. El propósito de esta investigación es obtener datos que puedan orientar la evaluación psicológica de las personas mayores. Para la obtención de los datos se buscó información sobre el desarrollo humano, y sobre la infección del virus de la malaria, a través de libros y artículos. Se buscaron instrumentos que se utilizan en la evaluación psicológica para recolectar información que mida las habilidades cognitivas y las funciones ejecutivas, conduciendo al conocimiento de estos constructos en el marco teórico de Papalia, D. E, Olds. S. W, \& Feldman, RD (2006) Desarrollo humano y Charchat-Fichman, Helenice et al. (2005). Disminución de la capacidad cognitiva durante el envejecimiento. A través de los resultados encontrados, se 
reconoció que la evaluación psicológica necesita más investigación sobre este tema, la cognición y la malaria. Se concluye que a través de nuevos estudios pueden aparecer más instrumentos psicométricos.

Palabras clave: Cognición; Anciano; Paludismo por P. vivax.

\section{Introdução}

O Presente artigo com tema Avaliação Cognitivo em idosos infectados por malária tem por objetivo trazer dados bibliográficos que trazem informações sobre o presente tema, dando ferramentas para uma melhor elucidação na fase do envelhecimento e quais os possíveis prejuízos cognitivos causados pela infecção da malária para assim construir ferramentas que possam ajudar em uma melhor qualidade de vida para o idoso, sabendo que esta população cresce de forma tal faltando apoio em várias esferas, como social, politico e familiar, sendo negligenciado por estes segundo Sousa (2009).

No tocante percebeu-se que no Estado do Amazonas possuem vários obstáculos além dos mencionados á cima, como a questão geográfica e as endemias como a malária, Ribeiro (2008), e Moraes, (2019), desta forma um dos vírus que tem muito atingindo esta população é da plamodium Vivax, surgindo então uma preocupação aos prejuízos cognitivos que podem causar nos idosos, já se sabe que em alguns estudos demonstrou danos cognitivos em escolares que tiveram a infecção por malária p. Vivax, Arruda et al. (2016), Moreira et al. (2017).

Entende-se a enorme carência de pesquisas voltadas aos idosos que tiveram a infecção por p.vivax que é o mais predominante na região Amazônica, pois esta população vem crescendo e poucas pesquisas com este tema são disponíveis no que tange malária e cognição.

Com a avaliação psicológica como uma ferramenta de uso exclusivo do psicólogo e as crescentes buscas por materiais para melhorar a qualidade de vida e o bem está social, viu-se a necessidade de buscar por pesquisas que trouxesse informações e conduzisse uma melhor forma de trabalho com qualidade e responsabilidade, sabendo que cada passo que envolve o sujeito e suas subjetividades traz uma obrigação de cumprir seu dever que ético sem medir esforços para assim o fazer Cfp (2019).

Conforme orientação do Sistema de Avaliação de Testes Psicológicos (SATEPSI) pesquisou-se sobre testes favoráveis, que podem ser utilizados e são de uso exclusivos dos psicólogos Cfp (2018). Uma vez observada a normativa, é justo considerar o emprego dos mesmos para trazer informações e servir de guia para mensurar os processos que envolvem a cognição do idoso, para assim ter um melhor direcionamento.

Por tanto houve uma preocupação quanto as formas de se identificar os possíveis danos cognitivos, sabendo que através da cognição é possível a autonomia e resolução de tarefas podendo se tornar mais restritos e dificultosos, devido algum prejuízo cognitivo, Charchat-Fichman et al. (2003) sendo a perda da memória uns dos responsáveis pela falta de autogovernase, Abreu (2005), et. al. Grosman et all. (1997) Abreu (2005).

Sabendo que as capacidades cognitivas na meia-idade sofrem declínios conforme o cérebro passa pelo processo de envelhecimento, muitas das tarefas requerem um tempo de reação rápida ou equilibrista, Papaia (2005), quando o idoso é acometido por alguma endemia tropical que é comum á região Amazônica, torna-se mais oneroso devido á necessidade de locomoção e medicação, muitos até perdem a vida quando não tratados adequadamente, segundo OPAS/OMS BRASIL.

O presente artigo trará informações sobre como acontece à infecção pelo vírus da malária e quais sintomas apresenta, porque tem pendurado por tanto tempo este vírus e de forma tão veemente atingindo a população não somente brasileira mais mundial, será abordado quais implicações corroboram para este vírus acometer principalmente a população amazônica Sousa (2009), Monteiro et al. (2011). 


\section{Quadro Teórico}

\subsection{A malária e seu percurso na história}

A malária é uma doença parasitária e infecciosa causada pelo parasita Plasmodium, que é transmitido pela picada do mosquito Anopheles fêmea infectado. Sendo os dois parasitas da malária mais comuns em humanos o Plasmodium falciparum e Plasmodium vivax, que divergem em sua manifestação clínica e distribuição geográfica Lacerda et. al. (2012).

Seus sintomas se dão principalmente por febre precedida de calafrios, seguida de sudorese profusa, fraqueza e cefaleia, que ocorrem em padrões cíclicos, dependendo da espécie de plasmódio infectante. Em alguns pacientes, surgem sintomas correspondentes, vários dias antes dos ápices da doença, a exemplo de náuseas, vômitos, astenia, fadiga e anorexia, OPAS/OMS BRASIL.

Quando não tratada adequadamente, pode evoluir para a forma grave, com febre superior a $41^{\circ} \mathrm{C}$, convulsão, hiperparasitemia, hiperpirexia, anemia intensa, icterícia, hemorragias e hipotensão arterial, vômitos repetidos, oligúria, dispneia, alteração de consciência, delírio, coma e até mesmo óbito Braz et al. (2010).

Segundo França et. al. (2008) existe várias citações na literatura antiga e das civilizações modernas que relatam febres malignas intermitentes e calafrios consistentes com os sintomas da malária, percebendo que não é uma endemia tão recente, mas que tem tirado muitas vidas durantes o decorrer dos anos, e a pesar de avanços no combate á infecção tem se mostrado forte inimigo do homem.

Tabela 1 - Histórico da malária.

\begin{tabular}{|c|c|c|}
\hline 2.700 a.C & O Canon O Nei Ching & $\begin{array}{l}\text { Sintomas da malária e as relações entre } \\
\text { febres e melancolias prolongadas }\end{array}$ \\
\hline \multirow[t]{3}{*}{ VI a.C } & $\begin{array}{l}\text { Manuscritos escavados da } \\
\text { biblioteca real de assurbanapoli em } \\
\text { Nínive (hoje Iraque) }\end{array}$ & Mencionaram Febres Mortais. \\
\hline & Shakespeare relatou em seus livros & Relatou sobre a malária \\
\hline & Fisiologista Hipócrates $\quad$ grego & 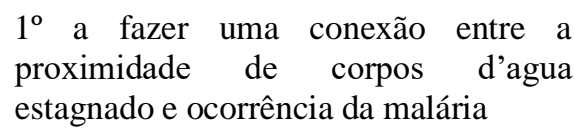 \\
\hline \multirow[t]{2}{*}{ XIV } & $\begin{array}{l}\text { Area cattiva ou malária (ar ruim) } \\
\text { italiana }\end{array}$ & Referiam-se a malária \\
\hline & $\begin{array}{l}\text { Paludismo pelos } \quad \text { franceses } \\
\text { (pântano) }\end{array}$ & Referiam-se a malária \\
\hline $\begin{array}{l}200 \text { anos depois } \\
\text { XIV }\end{array}$ & $\begin{array}{lll}\text { Santo } & \text { Agostinho, } & 1^{\circ} \\
\text { Arcebispo } & \end{array}$ & Morreu de Febre Maligna \\
\hline 597 a.C & de Canterbury. & \\
\hline 1321 d.C & Dante Alghieri, poeta italiano. & Morreu de malária \\
\hline 1558 & $\begin{array}{l}\text { Carlos V, Imperador do Sacro } \\
\text { Império Romano Germanico. }\end{array}$ & $\begin{array}{llll}\text { Morreu } & \text { de } & \text { Febre } & \text { dos } \\
\text { Pântanos } & & & \end{array}$ \\
\hline 1590 & Papa Sixtos V & $\begin{array}{llll}\text { Morreu } & \text { de } & \text { Febre } & \text { dos } \\
\text { Pântanos } & & & \end{array}$ \\
\hline
\end{tabular}




\begin{tabular}{|c|l|l|}
\hline 1720 & $\begin{array}{l}\text { Pedro o grande proibiu o exército } \\
\text { de comer melões e frutas que } \\
\text { acreditava estava matando o } \\
\text { exercito }\end{array}$ & Exército estava morrendo de febre \\
\hline XVIII e XIX & $\begin{array}{l}\text { Expansão das colônias para o } \\
\text { interior da América do Norte }\end{array}$ & $\begin{array}{l}\text { Malária foi junto, endêmicas na parte } \\
\text { sudestes e oeste das colônias norte- } \\
\text { americanas. }\end{array}$ \\
\hline $\mathbf{1 6 0 7}$ & $\begin{array}{l}\text { Os ingleses introduziram na } \\
\text { américa duas espécies . }\end{array}$ & $\begin{array}{l}\text { Duas espécies de malária Pasmodium } \\
\text { Vivax e plasmodium malarial. }\end{array}$ \\
\hline $\mathbf{1 6 2 0}$ & $\begin{array}{l}\text { Importação de escravos da África } \\
\text { Plasmadium falciparum para } \\
\text { continente }\end{array}$ \\
\hline
\end{tabular}

Fonte: França et., al (2008).

Conforme a tabela 1 á cima, onde França et., al. (2008) afirma que a malária sempre esteve presente na história afetando inclusive papa, sendo forte inimigo até mesmo dos grandes exércitos que foram devastados pela infecção malárica, França et. al (2008) cita em seu artigo que acredita-se que Alexandre o grande no auge do seu poder aos 33 anos morreu da febre maligna quando partia com seu exército, atualmente a malária tem sido forte obstáculo para qualquer exercito como no caso do Brasil comenta o autor.

Camargo (2003) afirma que a primeira e a segunda epidemia amazônica de malária se deu com a imigração nordestina á Amazônia, o autor comenta que a história da malária no Brasil estar abraçado com diversos acontecimentos históricos, como a borracha no século XIX e a Construção da estrada de ferro Madeira- Mamoré, ocorrida entre os anos de 1907 e 1912 atraindo os imigrantes em busca de formas de trabalho.

\subsection{Processo de envelhecimento}

O envelhecimento populacional é um fenômeno mundial que acarreta grandes desafios à Saúde Pública em um contexto social, uma vez que o aumento do número de anos na vida dos brasileiros precisa ser acompanhado para melhoria ou manutenção da saúde e qualidade de vida. Até 2025, de acordo com a Organização Mundial de Saúde (OMS), o Brasil será o sexto país do mundo em número de idosos.

A população idosa (60 anos e mais) que era de 2,6 milhões de pessoas em 1950 (5\% da população total) passou para 19,8 milhões em 2010 (10\% do total) e estima- se que deva chegar a 67 milhões em 2050 (quase 30\% do número total de habitantes do país). Entre 1980 e 2000 a população com 60 anos ou mais cresceu 7,3 milhões, totalizando mais de 14,5 milhões em 2000, Braz (2010).

\subsection{O cérebro e o processo de envelhecimento}

Os autores Papalia et., al. (2013) apud Madden et., al. (2008) referencia em seu livro sobre desenvolvimento humano que o cérebro em processo de envelhecimento experimenta declínios em uma série de áreas que envolvem múltiplas tarefas que exigem reações rápidas ou habilidades complexas envolvendo muitos estímulos. Onde se dá por razões de alterações físicas reais no cérebro, como o fenômeno na ponta da língua (TOT-tip-of-the-tongue) em que uma pessoa sabe que sabe uma palavra, mas não consegue acessá-la na memória, afirma os autores.

O uso de TOTs muito frequentemente, pode se dá pelas pessoas que são propensas a apresentar a maior quantidade de atrofia na ínsula esquerda, uma área do cérebro associada á produção da fala, afirmam Papalia et., al. (2013); apud Shafto et., 
al. (2007). Com a degeneração da mielina, a bainha de gordura que envolve nosso cérebro, por causa da idade, o cérebro começa funcionar mais lentamente como é percebido Papalia et., al. (2013) apud Bartzokis et., al (2008).

\subsection{O idoso da Amazônia}

Já em contexto amazônico, o fenômeno do envelhecimento é ainda mais delicado, uma vez que para ser adequadamente discutido, deve considerar a sociodiversidade etino cultural dessa região. Braz (2010) segundo seus relatos uma população estimada em cerca de 10 milhões maioritariamente concentrada em áreas urbanas ao longo do rio e seus principais afluentes, os idosos que povoam da Bacia do Rio Amazonas compõe um universo de indivíduos que vivem em áreas com pouco acesso aos cuidados de saúde e que não tem sido bem estudada.

Por tanto uma das causas da incipiência de estudos epidemiológicos abordando a realidade dos idosos nesta região, esta relacionada com as dificuldades associadas às características geográficas e ecológicas da região amazônica, e os poucos recursos destinados ás mesmas, já que a maior parte desta população é composta de pessoas carentes.

Segundo Braz (2010) o processo de envelhecimento na região Norte do País dá- se em um contexto de desigualdades regionais e sociais, pobreza e fragilidade de instituições onde os idosos não encontram assistência satisfatória de políticas públicas, fazendo que só se agrave ás condições de saúde nesta fase da vida que parece e acaba se tornando tão difícil.

Envelhecer na Amazônia está associado a uma série de questões cruciais para pesquisadores dos sistemas de saúde, uma vez que é uma região que apresenta uma maior prevalência de Doenças Crônicas não transmissíveis (DCNT) por ser uma região desfavorecida significativamente do ponto de vista socioeconômico comenta Sousa (2009).

Importante considerar que por mais que o fenômeno do envelhecimento seja uma realidade global, no que compete ajuizar sobre ele na região norte do Brasil é algo dificultoso, uma vez que estudos sobre os idosos que vivem nesta região do Brasil são incipientes e deve ser realizado para subsidiar políticas públicas de saúde, Sousa (2009).

No que compete a dados relacionados ao envelhecimento na Cidade de Manaus, é válido citar que estudos demonstram que os idosos aqui residentes apresentam alta prevalência de doenças crônicas; ainda sobre o envelhecer na capital amazonense, estudo observou que a velhice é notadamente marcada por pobreza por uma grande parcela da população, com a realidade de vínculos afetiva familiar deficitária e sem garantia de seguridade social. Um estudo comparativo entre idosos de Porto Alegre e de Manaus, demonstrou ainda que na capital amazonense há uma menor auto percepção de saúde, Cauduro (2013).

\subsection{Envelhecimento e cognição}

Segundo Argman (2006) as mudanças no cérebro do idoso saudável são modestas e fazem poucas diferenças no funcionamento, afirmando que quando existe um problema que esteja relacionado com o Sistema Nervoso Central, este pode interferir na cognição.

Nas habilidades cognitivas Argiman (2006) et. at.; apud Papalia descreve que dos 65 anos aos 75 anos algumas das mudanças cognitivas são sutis ou até inexistentes como é o caso do conhecimento de vocabulário, entretanto, ocorrem declínios importantes nas medidas que envolvem velocidades ou habilidades não exercitadas Argiman (2006) et. at.; apud Papalia.

No que se refere á saúde mental afirma quere o declínio nesta área é típico na terceira idade, porém a doença mental é mais comum no adulto jovem do que no adulto mais velho. Segundo os autores, "as pessoas podem e efetivamente continuam a adquirir novas informações e habilidades que já conhecem”. Argiman (2006) et. at.; apud Papalia destacam ainda que "... o inicio da senescência varie bastante e justificam através da teoria biológica do envelhecimento e das teorias de programação genética". A justificativa de Argiman (2006) et. at.; apud Papalia é de que "por um plano normal de desenvolvimento embutido 
nos genes, os corpos envelhecem, salientando, portanto, que, cada espécie tem sua própria expectativa de vida e padrão de envelhecimento".

\section{Metodologia}

O método adotado foi por pesquisa do tipo exploratória- descritiva com a abordagem qualitativa e o método dialético, pois visando a complexidade a ser pesquisada e os vários aspectos que o cercam, através da investigação, reflexão e ao estudo das percepções e práticas dos sujeitos, tanto pesquisadores, como o fenômeno social, para ter uma maior compreensão destes fenômenos a partir do contexto em que estes se encontram, afirma Bogdan \& Biklen, (1994), através dos dados coletados através de pesquisas bibliográficas em idosos e sua relação com possíveis danos cognitivos, onde se buscou comparar dados conceituais de diferentes autores que abordaram este tema, procurou-se por pesquisas voltadas á região amazônica dada à relevância endêmica na região, no período de 20 de Janeiro de 2019 a 28 de Junho de 2019, fazendo uma comparação entre os dados conceituais coletados pelos autores.

Cervo e Silva (2006) dizem em seu trabalho que a pesquisa exploratória estabelece critérios, métodos e técnicas para a elaboração de uma pesquisa e visa oferecer informações sobre o objeto desta e orientar a formulação de hipóteses. Em relação a descritiva Barros e Lehfeld (2007) afirmam que realiza-se o estudo, a análise, o registro e a interpretação dos fatos do mundo físico sem a interferência do pesquisador.

Priorizou-se por dados conceituais que envolvesse as questões cognitivas dos idosos e seu funcionamento, por referências científicas sobre a malária, dados atualizados sobre o envelhecimento e quais implicações tem sofrido pelas endemias tropicais. Buscou- se por instrumentos que a avaliação psicológica se utiliza para coletar dados para direcionar futuras pesquisas, observando e priorizando o idoso e a cognição.

As coletas de dados bibliográficos sobre a infecção malárica em idosos e sua relação com possíveis danos cognitivos, onde se buscou comparar dados conceituais de diferentes autores que abordaram este tema, procurou-se por pesquisas voltadas á região Amazonônica dada à relevância endêmica na região, no período de 20 de Janeiro de 2019 a 28 de Junho de 2019, fazendo uma comparação entre os dados conceituais coletados pelos autores. Priorizou-se por dados conceituais que envolvesse as questões cognitivas dos idosos e seu funcionamento, por referências científicas sobre a malária, dados atualizados sobre o envelhecimento e quais implicações tem sofrido pelas endemias tropicais. Buscou- se por instrumentos que a avaliação psicológica se utiliza para coletar dados para direcionar futuras pesquisas, observando e priorizando o idoso e a cognição.

\section{Discussão dos Resultados}

Diante dos dados bibliográficos obtidos se observou que é insuficiente dado á relevância no contexto amazônico, pois são poucas pesquisas disponíveis em relação à malária, cognição em idosos, com a população brasileira cada vez mais idosa as políticas públicas não demonstram o interesse necessário para atender as demandas, o que não impede de trazer á observação que os novos estudos podem focar a este tema em questão, onde a negligência poderá ser diluída frente à sociedade que não poderia se calar diante da realidade que saltam aos os olhos.

Entende-se que uma das dificuldades estar relacionada com as alterações cognitivas, onde na maioria das vezes são confundidas com o processo natural do envelhecimento retardando o seu diagnóstico e tratamento. A tecnologia e suas consequentes mudanças crescem a cada ano, porém, não percebe o idoso, pois devido suas limitações acabam se tornando cada vez mais dependentes. Zimerman (2007). Os critérios objetivos e subjetivos associados a normas e valores sociais e individuais Beckert et., al, (2012) são primícias que todo profissional deve observar, para levar qualidade de vida para este prolongamento 
que já foi alcançado.

A Organização Mundial da Saúde trás estimativas, que 40\% da população mundial, pois residem em áreas de risco de transmissão da malária. Onde aproximadamente 214 milhões de pessoas foram infectadas no ano de 2015, com 438.000 mortes, dados que precisam ser observados com muita atenção

\section{Considerações Finais}

A carência de estudos que associem o prejuízo cognitivo pela infecção por P.vivax em idosos Arruda et al. (2016); Moreira et al. (2017) foi o impulsionar para este trabalho, despertar o interesse que já se faz presente mas de forma tímida, sabendo que quadro parasitários, como a infecção malárica podem produzir perturbações como descreve Gazzinelli et al. (2016); Da Silva et al. (2017).

Portanto para uma vida saudável e de qualidade, ainda que a velhice tenha suas limitações, não se deve parar a busca por este tão idealizado ser feliz, pois uma realidade não muito otimista no que se diz respeito cuidar da população idosa que cada vez mais cresce neste país, pois muitas questões de saúde voltada esta população é negligenciada.

Cabe aos estudiosos este papel, sem medir esforços para finalmente conseguir uma ciência que seja além dos artigos, mas vivenciada na vida de cada pessoa que talvez pense não ter muito que esperar do amanha, quando na verdade a plasticidade de um cérebro saudável depende da forma que cada sujeito lhe da com suas habilidades, que com toda certeza cada idoso tem, conforme afirma Papalia et. al. (2013).

Estudos fazem menção da estimulação cognitiva para idosos, Ribeiro et. al. (2002); Beckert, Irigaray, Trentini (2012) o quanto pode beneficiar esta população, porém, não são implantadas formas para levar essas estimulações aos idosos, principalmente aos menos favorecidos, que dependem de viagens longas por exemplos param se dirigirem a determinadas instituições quando necessitam. Salientam-se essas inquietudes para que novas pesquisas sirvam de base para a questão "idoso malária e cognição", pois a população amazonense vivencia cada um desses mencionados, e além dessas questões foi mencionado anteriormente, existem as necessidades socioeconômica, geográfica e dentre outras, que também devem ser observadas, com um olhar clínico, investigativo e científico.

\section{Referências}

Abreu N et al. Neuropsicologia da aprendizagem e memória. In: Fuentes et al. Neuropsicologia teoria e prática. $2^{\mathrm{a}}$ edição (pp 103-114). Porto Alegre:Artmed, 2014.

Argimon, Irani I. de Lima. Aspectos cognitivos em idosos. Aval. psicol., Porto Alegre, dez. 2006. http://pepsic.bvsalud.org/scielo.php?

Arruda, Eder Ferreira de et al. Associação entre malária e anemia em área urbana de transmissão do Plasmodium: Mâncio Lima, Acre, Brasil. Cadernos de Saúde Pública, v. 32, p. e00115514, 2016.

Atalaia-silva, Kelly Cristina \& Lourenço, Roberto Alves. Tradução, adaptação e validação de construto do Teste do Relógio aplicado entre idosos no Brasil. Revista de Saúde Pública, v. 42, p. 930-937, 2008.

Beckert, Michele; \& Marceli. Qualidade de vida, cognição e desempenho nas funções executivas de idosos. Estudos de psicologia, v. 29, n. 2, p. 155-162, 2012 .

Bogdan, R. C.; Biklen, S. K Investigação Qualitativa em Educação: uma introdução á teoria e aos métodos. Ponto - Porto Editora. 1994

Braz, Rui Moreira; \& Tauil, Pedro Luiz. Caracterização das epidemias de malária nos municípios da Amazônia Brasileira em 2010. Cad. Saúde Pública, Rio de Janeiro, v. 29, n. 5, p. 935-944, May 2013. http://www.scielo.br/scielo.php?

Cauduro, A., Bós, Â. J. G., \& Cauduro, M. H. F. (2013). Fatores associados a morar sozinho e suas diferenças regionais em idosos residentes de Porto Alegre e Manaus. Estudos Interdisciplinares sobre o Envelhecimento, 18(2).

Camargo, Erney Plessmann. Malária, Maleita, Paludismo. Ciência e Cultura, v. 55, n 1. Jan/Mar 2003. 36-30.

Cosenza, RM, (Ed,), Neuropsicologia teoria e prática. $2^{\text {a }}$ edição (pp 115-138). Porto Alegre: Artmed,2014. 
Research, Society and Development, v. 10, n. 3, e7310313247, 2021

(CC BY 4.0) | ISSN 2525-3409 | DOI: http://dx.doi.org/10.33448/rsd-v10i3.13247

Cotta, Mariana Fonseca et al. O Teste de Aprendizagem Auditivo-Verbal de Rey (RAVLT) no diagnóstico diferencial do envelhecimento cognitivo normal e patológico. Contextos clínicos, v. 5, n. 1, p. 10-25, 2012

Duncan, B.B. et al (org). Medicina Ambulatorial: Condutas de atenção primaria baseadas em evidências. 4 ed. Porto alegre: Artmed, 2013.

Foss, M. P.; B. M. S.; \& Speciali, J. G. Figuras Complexas de Rey para idosos. Avaliação psicológica, vol. 9, n. 1., p. 53-61, 2010.

Ferreira, Vinícius Renato Thomé; Mousquer, Denise Nunes. Observação em psicologia clínica. Revista de Psicologia da UNC, v. 2, n. 1, p. 54-61, 2004.

Gazzinelli, Maria Flávia et al. Aprendizagem, cognição e educação em saúde: estudo em área endêmica para helmintoses. Psicologia, Saúde \& Doenças, v. 17, n. 3, p. 326-337, 2016.

Hutz, C. S.; Bandeira, D. R.; Trentini, C. M. Psicometria. Porto alegre: Artmed, 2015

Kandel, ER et, al. Princípios de neurociências. $5^{\circ}$ edição. Porto Alege: AMGH,

2014.

Malloy-Diniz, L. F.; \& cosenza, R. 2000. O teste de Aprendizagem Auditivo-Verbal de Rey: Normas para uma população brasileira. Revista Brasileira de Neurologia. Ministerio, da Saúde Secretaria da Vigilância em saúde. Guia para profissionais de saúde. Brasília, 2008

Monteiro, Maria Rita de Cassia Costa; RIBEIRO, Mayani Costa; FERNANDES, Suellen Costa. Aspectos clínicos e epidemiológicos da malária em um hospital universitário de Belém, Estado do Pará, Brasil. Rev Pan-Amaz Saude, Ananindeua, v. 4, n. 2, p. 33-43, jun. 2013. http://scielo.iec.gov.br/scielo.

Nascimento, Roseane Aparecida Sant' Ana do et al. Prevalência e fatores associados ao declínio cognitivo em idosos com baixa condição econômica: estudo Monidi. J. bras. psiquiatr., Rio de Janeiro, Sept. 2015. http://www.scielo.br/scielo.php?script=sci_

Papalia, D. E.; Feldman, R. D. Desenvolvimento Humano. 12 edição. Porto Alegre: AMGH, 2013.

Ribeiro, Rita de Cassia Lanes et al. Capacidade funcional e qualidade de vida de idosos. Estudos Interdisciplinares sobre o Envelhecimento, v. 4, 2002.

Shatile, Cognite training improves sleep quality and cognitve funcntion among older adults, 2013.

Satepsi. Sistema de Avaliação de Testes Psicológicos (SATEPSI), satepsi.cfp.org.br.

Zimerman, Guite I. Velhice: aspectos biopsicossociais. Porto Alegre: Artmed, 2007. 